\title{
Wnt Signaling Behaves as a "Master Regulator" in the Osteogenic and Adipogenic Commitment of Human Amniotic Fluid Mesenchymal Stem Cells
}

\author{
Iolanda D'Alimonte - Angela Lannutti • \\ Caterina Pipino • Pamela Di Tomo • \\ Laura Pierdomenico • Eleonora Cianci • \\ Ivana Antonucci - Marco Marchisio • Mario Romano • \\ Liborio Stuppia - Francesco Caciagli • \\ Assunta Pandolfi • Renata Ciccarelli \\ Published online: 19 April 2013 \\ (C) The Author(s) 2013. This article is published with open access at Springerlink.com
}

\begin{abstract}
Human amniotic fluid mesenchymal stem cells (huAFMSCs) are emerging as a promising therapeutic option in regenerative medicine. Here, we characterized huAFMSC phenotype and multipotentiality. When cultured in osteogenic medium, huAFMSC displayed a significant increase in: Alkaline Phosphatase (ALP) activity and
\end{abstract}

Iolanda D'Alimonte, Angela Lannutti, Assunta Pandolfi and Renata Ciccarelli equally contributed to the study

I. D'Alimonte - A. Lannutti - C. Pipino - P. Di Tomo • E. Cianci •

M. Romano $\cdot$ F. Caciagli $\cdot$ A. Pandolfi $\cdot$ R. Ciccarelli

Department of Experimental and Clinical Sciences,

University "G. D'Annunzio" of Chieti-Pescara, Chieti, Italy

L. Pierdomenico $\cdot$ M. Marchisio

Department of Medicine and Aging Sciences,

University "G. D'Annunzio" of Chieti-Pescara, Chieti, Italy

I. Antonucci $\cdot$ L. Stuppia

Department of Psychological Sciences, Humanities and Territory,

University “G. D'Annunzio" of Chieti-Pescara, Chieti, Italy

I. D'Alimonte · A. Lannutti $\cdot$ C. Pipino $\cdot$ P. Di Tomo $・$

L. Pierdomenico $\cdot$ E. Cianci $\cdot$ I. Antonucci $\cdot$ M. Marchisio $\cdot$

M. Romano $\cdot$ L. Stuppia $\cdot$ A. Pandolfi $\cdot$ R. Ciccarelli

StemTeCh Group, Chieti, Italy

C. Pipino $\cdot$ P. Di Tomo $\cdot$ L. Pierdomenico $\cdot$ E. Cianci $\cdot$

M. Marchisio $\cdot$ M. Romano $\cdot$ L. Stuppia $\cdot$ F. Caciagli •

A. Pandolfi $\cdot$ R. Ciccarelli

Center for Aging Sciences (Ce.S.I), “G. D’Annunzio University

Foundation", Chieti, Italy

R. Ciccarelli $(\bowtie)$

Department of Experimental and Clinical Sciences,

Section of Pharmacology, Via dei Vestini 29,

66100 Chieti Scalo, Italy

e-mail: r.ciccarelli@unich.it
mRNA expression, Alizarin Red S staining and Runx2 mRNA expression; whereas maintaining these cells in an adipogenic culture medium gave a time-dependent increase in PPAR $\gamma$ and FABP4 mRNA expression, glycerol-3phosphate dehydrogenase (GPDH) activity and positivity to Oil Red Oil staining. These results confirm that huAFMSCs can differentiate toward osteogenic and adipogenic phenotypes. The canonical Wnt/Bcatenin signaling pathway appears to trigger huAFMSC osteoblastogenesis, since during early phases of osteogenic differentiation, the expression of Dishevelled-2 (Dvl-2), of the nonphosphorylated form of $\beta$-catenin, and the phosphorylation of glycogen synthase kinase-3ß (GSK3ß) at serine 9 were upregulated. On the contrary, during adipogenic differentiation Dvl-2 expression decreased, whereas that of B-catenin remained unchanged. This was associated with a late increase in GSK3ß phosphorylation. Consistent with this scenario, huAFMSCs exposure to Dickkopf-1, a selective inhibitor of the Wnt signaling, abolished Runx2 and ALP mRNA upregulation during huAFMSC osteogenic differentiation, whereas it enhanced FABP4 expression in adipocytedifferentiating cells. Taken together, these results unravel novel molecular determinants of huAFMSC commitment towards osteoblastogenesis, which may represent potential targets for directing the differentiation of these cells and improving their use in regenerative medicine.

Keywords Human amniotic fluids · Mesenchymal stem cells · Osteogenic/adipogenic differentiation $\cdot$ Wnt signaling

$\begin{array}{ll}\text { Abbreviations } & \\ \text { AF } & \text { Amniotic fluid } \\ \text { APC } & \text { Allophycocyanin-conjugated }\end{array}$

Abbreviations

APC Allophycocyanin-conjugated 


$\begin{array}{ll}\text { ALP } & \text { Alkaline phosphatase } \\ \text { ARS } & \text { Alizarin Red S } \\ \text { DKK-1 } & \text { Dickkopf-1 } \\ \text { DMEM } & \text { Dulbecco-Modified Essential Medium } \\ \text { Dvl } & \text { Dishevelled } \\ \text { FABP4 } & \text { Fatty acid binding protein } 4 \\ \text { FBS } & \text { Foetal Bovine Serum } \\ \text { FITC } & \text { Fluorescein isothiocyanate-conjugated } \\ \text { GPDH } & \text { Glycerol-3-phosphate dehydrogenase } \\ \text { GSK-3 } \beta & \text { Glycogen synthase kinase-3 } \beta \\ \text { hu-AFMSCs } & \text { Human-amniotic fluid derived } \\ & \text { mesenchymal stem cells } \\ \text { IBMX } & 3 \text {-isobutyl-1-methylxanthine } \\ \text { MEM } & \alpha \text {-Minimal Essential Medium } \\ \text { MFI } & \text { Mean Fluorescence Intensity } \\ \text { MSCs } & \text { Mesenchymal stem cells } \\ \text { PE } & \text { Phycoerithrin } \\ \text { PPAR } \gamma & \text { Peroxisome proliferator-activated } \\ & \text { receptor- } \gamma \\ \text { PBS } & \text { Phosphate saline buffer } \\ \text { RUNX-2 } & \text { Runt-related transcription factor-2 } \\ \text { RT } & \text { Room temperature } \\ \text { SDS } & \text { Sodium dodecyl sulphate } \\ \text { Wnt } & \text { Wingless }\end{array}$

\section{Introduction}

Mesenchymal stem cells (MSCs) possess high self-renewal capacity and multipotency $[1,2]$. These characteristics make these cells a promising resource in tissue engineering and regeneration. Indeed, accumulating evidence indicates that MSCs can treat bone damage [3-5] as well as a variety of other diseases [reviewed in [6]. One limiting factor for the use of MSCs is their availability, since they are represented at low frequency, which further decreases with aging [7], in the bone marrow and dental tissue. Moreover, collection from these sites requires invasive procedures associated with pain and morbidity. Therefore, the isolation from more accessible sources of MSCs that can be expanded to large numbers, and carry a good multi-lineage differentiation potential, would be ideal.

The human amniotic fluid (huAF) has been recently proposed as source of stem-like cells [8,9]. These cells, termed human AF-derived MSCs (huAFMSCs), show a higher proliferation rate and differentiation potential, compared to adult stem cells [10-13] and have the advantage of being primitive cells with very low risk of tumor development and no evident antigenicity [14, 15]. Therefore, huAFMSCs are employed as a tool for basic research and studied in prevision of their use for cell-based therapies [16, 17], although some irregularities in their epigenetic control system detected at late-passages suggest that for therapeutical purposes these cells should be used at early stages of culture [18]. Additionally, mid-trimester huAFSCs may show pluripotency gene expression upon switch of culture conditions and form tumors [19]. This evidence imposes caution although tumorigenicity of huAFMSCs has been excluded by a number of studies [17, 19, 20].

In vitro, osteogenic or adipogenic differentiation of huMSCs recapitulates many of the developmental steps during normal in vivo processes [21, 22]. A plethora of molecules have been identified to have a role in modulating stem cell fate [23]. Among them, the Wnt signaling is recognized as a key regulator of adult tissue homeostasis and remodeling [24] through multiple so called "canonical" and "non canonical" pathways. Wnt comprises a group of secreted glycoproteins that bind to the frizzled family of receptors as well as to low density lipoprotein-related protein (LRP) co-receptors (see [25] and references therein). While the non canonical pathway is still poorly defined, the canonical Wnt cascade converges on the transcriptional modulator $\beta$-catenin. The binding of Wnt ligands to cellsurface receptors of the Frizzled family inactivates a protein complex containing axin, the adenomatous polyposis coli protein (APC) and glycogen synthase kinase $3 \beta$ (GSK3 $\beta$ ), which normally primes phosphorylated $\beta$-catenin for ubiquitination and proteasomal degradation. As a consequence, non phosphorylated $\beta$-catenin accumulates in the cytoplasm from which it is translocated to the nucleus where it activates Wnt responsive genes. The canonical Wnt signal transduction pathway has been implicated in bone formation as Wnt signaling stimulates osteoprogenitor proliferation and osteogenesis (see $[26,27]$ for review). On the other hand, the Wnt signaling represses adipogenesis by blocking the induction of CCAAT/enhance-binding protein- $\alpha$ (CEBPA) and peroxisome proliferator-activated receptor- $\gamma$ (PPAR $\gamma$ ), two master adipogenic transcription factors. Conversely, disruption of the $\mathrm{Wnt} / \beta$-catenin signaling leads to spontaneous adipogenesis [28]. Although not unequivocally [29-31], the canonical Wnt signaling seems to be crucial for MSC cell commitment toward osteogenesis [32, 33]. Whether this also applies to huAFMSCs remains to be established.

\section{Materials and Methods}

\section{Materials}

Disposables for tissue culture were from Falcon (Steroglass, Perugia, Italy). Low and high glucose Dulbecco-Modified Essential Medium (DMEM) and Foetal Bovine Serum (FBS) were from PAA Culture Company (M-Medical, Milan, Italy); ascorbic acid, dexamethasone, 3-isobutyl-1- 
methylxanthine (IBMX), $\beta$-glycerophosphate disodium salt, Dickkopf-1 (DKK-1) as well as all the other chemicals, unless differently indicated, were from Sigma-Aldrich (Milan, Italy); human recombinant insulin was from ProSpec (Elettrofor, Rovigo, Italy). Human fibroblasts and optimized fibroblast medium were purchased from Lonza (Walkersville, MD, USA).

\section{Cell Culture}

Two or three milliliters of AF samples were obtained from 16 to 19 week pregnant women who underwent amniocentesis for fetal genetic determination in routine prenatal diagnosis. Cell samples were used only when a normal karyotype was detected by the cytogenetic analysis. All patients received detailed information about the experimental protocol, which was approved by the Ethics Committee of the University of Chieti, and each participant gave her written informed consent. Cells were immediately isolated from $\mathrm{AF}$ and debris by centrifugation at $150 \times \mathrm{g}$ for $10 \mathrm{~min}$ at room temperature (RT). The cell pellet was suspended with $5 \mathrm{ml}$ of DMEM low glucose with $20 \%$ of FBS, $1 \%$ penicillin/streptomycin (Invitrogen, Milan, Italy), $1 \%$ L-glutamine and $5 \mathrm{ng} / \mathrm{ml} \mathrm{b}-\mathrm{FGF}$, seeded on a T25 tissue culture flask, and incubated at $37^{\circ} \mathrm{C}$ in humidified $5 \% \mathrm{CO}_{2}$, $5 \% \mathrm{O}_{2}$ for 3-4 days. The medium and non-adherent cells were removed after 7 days and then every 3-4 days. The huAFMSCs were allowed to expand to $70 \%$ confluence and then routinely subcultured at 1:3 dilution. Cells were maintained in culture for up to 6-8 passages and used for all the experiments.

\section{Experimental Protocol}

Cells were seeded at $4 \times 10^{4}$ cell/well onto 6 -well plates to evaluate mineralization by Alizarin Red S (ARS) and non tissue specific alkaline phosphatase (ALP), whereas they were plated at $1 \times 10^{4}$ cell/well onto 24 -well plates to measure ALP and glycerol-3-phosphate dehydrogenase (GPDH) enzyme activities or at $25-50 \times 10^{4}$ cell/well onto $100 \mathrm{~mm}$ plates for immunophenotyping by flow cytometry; evaluation of osteogenic and adipogenic markers by real time PCR; and analysis of factors of the Wnt pathway by western blotting. Human fibroblasts, used as a control for osteogenesis induction and changes in the Wnt pathway, were plated at $1 \times 10^{6} \mathrm{cell} / \mathrm{well}$ onto $100 \mathrm{~mm}$ plates.

Assays were performed at different times, which were selected on the basis of indications from the literature or preliminary evidence, this leading to unavoidable temporal differences to measure the two differentiative processes. The Wnt antagonist DKK-1, when present, was administered to AFMSCs growing in non-differentiating or differentiating medium, starting $24 \mathrm{~h}$ after seeding. Afterwards, it was added to the cultures at each medium change for the indicated period.

\section{Flow Cytometry}

To analyze the expression of typical cell surface and intracellular protein markers, adherent cells were incubated with anti-human primary antibodies as previously described [34]. Anti-CD13, -CD44, -CD45, -CD105, -CD166 fluorescein isothiocyanate-conjugated (FITC) and anti-CD29 phycoerythrin-conjugated (PE) were obtained from Ancell (MN, USA); anti-CD14-FITC and -CD133-PE were purchased from Miltenyi Biotec (Bergisch Gladbach, Germany); anti-CD90-FITC, -CD73-PE, -Sox2-Alexa488conjugated (Sox2-Alexa488), -SSEA4-FITC, -CD146$\mathrm{PE},-\mathrm{CT} 3 / 4-\mathrm{PE}$ and -CD117-allophycocyanin-conjugated (CD117-APC) were obtained from Becton Dickinson (BD, San Jose, CA); anti-CD144-FITC was from Acris Antibodies (Herford, Germany); anti-CD34-PE was purchased from Beckman Coulter (Fullerton, CA, USA); anti-hTERT primary antibody was obtained from Calbiochem (Dermastadt, Germany) and appropriate secondary FITCconjugated antibody was obtained from Jackson ImmunoResearch Laboratories (West Grove, PA, USA). At the end of the incubation, cells were washed, centrifuged, resuspended in $0.5 \%$ paraformaldehyde, incubated for $5 \mathrm{~min}$ at room temperature (RT), washed, centrifuged again and kept at $4{ }^{\circ} \mathrm{C}$ in the dark until analysis with a FACSCalibur flow cytometer (BD), using the CellQuest ${ }^{\mathrm{TM}}$ 3.2.1.f1 software (BD). Quality control was performed by a regular check-up with Rainbow Calibration Particles (BD Biosciences). Debris was excluded from the analysis by gating on morphological parameters; 20,000 non-debris events in the morphological gate were recorded for each sample. To assess non-specific fluorescence we used isotype controls. All antibodies were titrated under assay conditions and optimal photomultiplier voltages (PMT) were established for each channel [35]. Data were analysed using the FlowJo ${ }^{\text {TM }}$ software (TreeStar, Ashland, OR). Mean Fluorescence Intensity Ratio (MFI Ratio) was calculated dividing the MFI of positive events by the MFI of negative events [36].

\section{In Vitro Osteogenic and Adipogenic huAFSC} Differentiation

After seeding, huAFMSCs were maintained for 3 days with normal medium, which was then substituted with an Osteogenic Differentiation Medium, constituted of high glucose DMEM, $10 \%$ FBS, $1 \%$ penicillin/streptomycin, $0.05 \mathrm{mM}$ ascorbic acid, $10 \mathrm{mM} \beta$-glycerophosphate, $100 \mathrm{nM}$ dexamethasone, or with an Adipogenic Medium, containing highglucose DMEM, $10 \%$ FBS, $1 \%$ penicillin/streptomycin, 
$500 \mu \mathrm{M}$ IBMX, $1 \mu \mathrm{M}$ dexamethasone, $10 \mu \mathrm{M}$ insulin. Differentiation media were replaced twice a week. Human fibroblasts were grown in undifferentiating medium, included in the kit assay, for $24 \mathrm{~h}$ after plating, as indicated in the manufacturer's instructions. Then, the medium was switched to that used for huAFMSC osteogenic commitment and maintained for 3 days. Mineralization was evaluated by (ARS) staining and (ALP) activity assay, whereas adipogenic differentiation was monitored by GPDH activity and Oil Red Oil staining.

Quantification of Mineralization Visualization of calcium deposition and extracellular matrix mineralization was obtained by ARS staining assay performed after 21 days, as previously reported [37]. Stained monolayers were visualized by phase contrast microscope (Eclipse TS100, Nikon), equipped with D200 digital camera (Nikon). For staining quantification, samples were treated as previously described [38]. Briefly, $800 \mu 110 \%$ (v/v) acetic acid were added to each well; cells were incubated for 30 min with shaking, then removed by scraping, transferred into a $1.5-\mathrm{mL}$ vial and vortexed for $30 \mathrm{~s}$. The obtained suspension was overlaid with $500 \mu \mathrm{l}$ mineral oil (Sigma-Aldrich), heated to $85^{\circ} \mathrm{C}$ for $10 \mathrm{~min}$, then transferred to ice for $5 \mathrm{~min}$, carefully avoiding the opening of the tubes until fully cooled, and centrifuged at $20,000 \times \mathrm{g}$ for $15 \mathrm{~min}$. The samples were acidified $(\mathrm{pH}$ between 4.1 and 4.5$)$ with $200 \mu$ of $10 \%(v / v)$ ammonium hydroxide. Aliquots $(150 \mu \mathrm{l})$ were read in triplicate at $405 \mathrm{~nm}$ by a spectrophotometer (Spectramax SM190, Molecular Devices, Sunnyvale, CA, USA).

Alkaline Phosphatase Activity Assay Tissue-nonspecific ALP activity was determined as previously reported [39]. Cell monolayers were washed with PBS, lysed with $1 \mathrm{ml}$ of Tris buffer (10 mM, pH 7.5, $0.1 \%$ Triton X-100) and centrifuged (2,000 rpm; $1 \mathrm{~min})$. Then, $20 \mu \mathrm{l}$ of supernatant from each sample were combined with $20 \mu \mathrm{l}$ of $1 \mathrm{mM}$ pnitrophenyl phosphate (p-NPP, Sigma; solution at $\mathrm{pH} 10.3$ with $\mathrm{MgCl}_{2}$-diethanolamine buffer) substrate and dispensed into 96-well plates. The samples were incubated in the dark at RT for $30 \mathrm{~min}$. The reaction was stopped with $10 \mu \mathrm{l}$ of 2 $\mathrm{N} \mathrm{NaOH}$. The amount of $\mathrm{p}-\mathrm{NPP}$ released was measured as absorbance at $405 \mathrm{~nm}$ on a microplate spectrophotometer (Spectramax SM190). The protein content of each sample was determined by the BioRad protein assay (Bio-Rad Laboratories, Milan, Italy). The enzyme activity was expressed as nmoles of p-NPP released per mg of protein per $30 \mathrm{~min}$.

Quantification of Adipogenesis Staining with Oil Red O (Sigma) was performed 14 days after cell exposure to adipogenic medium to elicit fat vacuoles after commitment of huAFMSCs toward the adipose phenotype. Cells were washed twice with PBS, fixed with $4 \%$ formaldehyde for $10 \mathrm{~min}$ at room temperature, rinsed once with $3 \%$ isopropanol and stained for $1 \mathrm{~h}$ at RT with filtered Oil Red O staining solution. Cells were rinsed with water and then photographed by using a Cool-SNAPcf digital CCD camera (PhotoMetrics, Huntington Beach, CA). To quantify lipid accumulation, cells were incubated for 10 min with $100 \%$ isopropanol and the absorbance was measured at $500 \mathrm{~nm}$ using a microplate spectrophotometer (Spectramax SM190). Adipogenic differentiation was also verified by measuring the activity of the enzyme GPDH, that belongs to the triglyceride biosynthetic pathway and is highly induced during cell adipogenic differentiation [40]. The assay was performed by using a commercial kit (Takara Bio, Shiga, Japan) following the manufacturer's instructions.

\section{RNA Isolation and Real Time-PCR Analysis}

Osteogenic and adipogenic markers were evaluated by realtime PCR. To this end, total RNA was isolated using the RNeasy Plus Universal Mini Kit (Qiagen Inc., Valencia, CA) according to the manufacturer's instructions. The M-MLV Reverse Transcriptase reagents (Applied Biosystems) were used to generate cDNA. Real-Time PCR was carried out with the ABI Prism 7900 Sequence Detection System (Applied Biosystems, Foster City, CA, USA). HuAFMSC expression of Runt-related transcription factor-2 (RUNX-2) and ALP was evaluated after 3, 7 and 14 days in culture, whereas PPAR $\gamma$ and fatty acid binding protein 4 (FABP4) expression was assessed after 1, 3 and 10 days in culture. Expression levels in cells cultured with normal medium and with differentiating medium were compared. Commercially available TaqMan Gene Expression Assays (RUNX-2 Hs00231692_m1; ALP Hs01029144_m1; PPAR $\gamma$ Hs01115513_m1; FABP4 Hs01086177_m1) and the TaqMan Universal PCR Master Mix (Applied Biosystems, Foster City, CA, USA) were used according to standard protocols. Beta-2 microglobulin (B2M Hs99999907_m1) (Applied Biosystems, Foster City, CA, USA) was used for template normalization. Duplicate determinations were carried out for each sample.

\section{Western Blot Analysis}

To examine the levels of dishevelled-2 (Dvl-2), non phophorylated (at ser 33 and 37 and thr 41)- $\beta$-catenin (non-p- $\beta$-cat) and glycogen synthase kinase $3 \beta$ phosphorylated at serine 9 (p-GSK3 $\beta$, ser9) three downstream factors in the Wnt pathway, total protein extracts were prepared to perform western blot analysis as previously described [41, 42]. Protein concentration was determined by the BioRad protein assay. The antibodies used were: polyclonal rabbit anti-Dvl-2, 1:200 dilution (Santa Cruz Biotecnologies); antip-GSK3 $\beta$, ser9, 1:1,000 dilution and anti-non- $\mathrm{p}$ - $\beta$-cat, 1:1,000 dilution (both from Cell Signalling Technology) and 


\begin{tabular}{|c|c|}
\hline \multicolumn{2}{|c|}{ Phenotype of AFSC } \\
\hline Antigens & Phenotype \\
\hline CD13 & + \\
\hline CD29 & +++ \\
\hline CD44 & +++ \\
\hline CD73 & ++ \\
\hline CD90 & + \\
\hline CD105 & +1 \\
\hline CD133 & - \\
\hline CD146 & ++ \\
\hline CD166 & + \\
\hline CD34 & - \\
\hline CD117 & - \\
\hline CD14 & - \\
\hline CD45 & - \\
\hline CD144 & - \\
\hline OCT3/4 & + \\
\hline SSEA-4 & +++ \\
\hline Sox-2 & +++ \\
\hline h-TERT & ++ \\
\hline \multicolumn{2}{|c|}{$\begin{array}{l}- \text { - negative expression;+/- } \\
\text { low expression; + moderate } \\
\text { expression;++ positive;+++ } \\
\text { high expression; Cut-off MFI } \\
\text { Ratio positivity }>2,0 .\end{array}$} \\
\hline
\end{tabular}

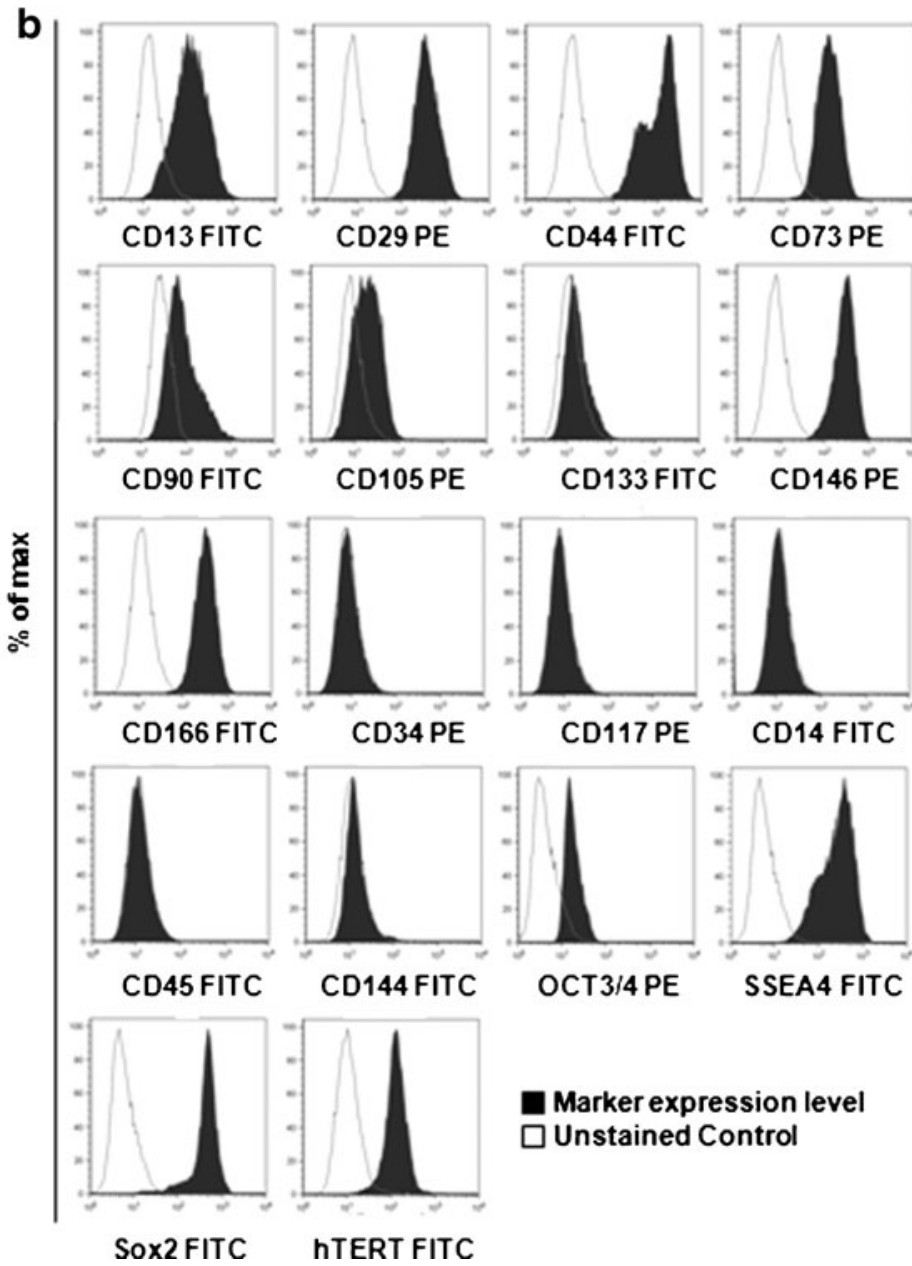

Fig. 1 Characterization of the immunophenotypic profile of undifferentiated huAFMSCs (panels a-b). Flow cytometric analysis was performed in cells previously incubated with fluorescent-conjugated antibodies against surface antigens (CD13, CD29, CD44, CD73, CD90, CD105, CD133, CD146, CD166, CD34, CD117, CD14, CD45, CD144) and intracellular antigens (OCT3/4, SSEA4, Sox-2 and hTERT). a Filled

donkey anti-rabbit HRP-conjugated secondary antibody (GE Healthcare Life Sciences; final dilution 1:5,000). To determine the equal loading of samples, the blots were stripped and re-probed with an anti- $\beta$-actin antibody (Santa Cruz Biotechnologies, 1:100 dilution). Immunocomplexes were visualised using the enhancing chemiluminescence detection system (GE Healthcare Life Sciences) and quantified by densitometric analysis (Molecular Analyst System).

Immunocytochemical Analysis

Cells were seeded in 24-well plates containing $12 \mathrm{~mm}$ round glass coverslips. After two washes with PBS, cells were fixed using freshly prepared $4 \%$ paraformaldehyde in PBS (10 min at RT), washed with PBS (5 min), and incubated with anti PPAR $\gamma$ rabbit monoclonal antibody (diluted 1:50; Cell Signaling) in NET gel $(150 \mathrm{mM} \mathrm{NaCl}, 5 \mathrm{mM}$ EDTA, histograms represent cells stained with the relevant antibody; open histograms show the correspective IgG isotype control (background control). b Table with a semi-quantitative evaluation of antigen expression, obtained dividing the mean fluorescence ratio (MFI) of positive events by the MFI of negative events. Data are representative of three independent samples obtained from 3 different donors

$50 \mathrm{mM}$ Tris-HCl, $\mathrm{pH} 7.4,0.05 \% \mathrm{NP}-40,0.25 \%$ carragenin lambda gelatin, $0.02 \% \mathrm{NaN}_{3}$ ) for $2 \mathrm{~h}$ at RT. After several washes, cells were incubated with a flourescein-conjugated anti rabbit secondary antibody (1:150 dilution; Jackson ImmunoResearch) in NET gel for $45 \mathrm{~min}$ at RT. After one wash with NET gel and one with PBS, samples were stained (5 min) with $0.5 \mu \mathrm{g} / \mathrm{ml}$ DAPI (in PBS), then washed with PBS, dried with ethanol $(70 \%, 90 \%, 100 \%)$ and finally mounted in glycerol containing 1,4-diazabicyclo[2.2.2]octane to minimize fading. Negative controls were represented by samples incubated with the secondary antibody only. Slides were observed with a 50i Eclipse microscope (Nikon) and images were acquired with a Cool-SNAP $c f$ digital CCD camera (PhotoMetrics, Huntington Beach, CA). Digital acquisition, processing and analysis of fluorescence were performed by Meta Image Series 7.5 (MetaMorph, Metafluor, MetaVue) software obtained from Molecular Devices [43]. 


\section{Statistical Analysis}

Experimental values are expressed as mean \pm SEM. Statistical significance was assessed by the Student's $t$ test using the Prism3 software (GraphPad, San Diego, CA, USA). $P$ values $<0.05$ were considered statistically significant.

\section{Results}

Immunophenotyping of huAFSCs

As shown in Fig. 1, HuAFMSCs did not display surface expression of haemopoietic markers (CD14, CD34 and $\mathrm{CD} 45)$. On the contrary, they expressed a variety of established mesenchymal markers (CD73, CD90, CD105), several surface adhesion molecules (CD29, CD44, CD146, CD166), and the stemness markers hTERT, Sox-2, Oct3/4 and SSEA-4. CD117 and CD133 were also not expressed, in accordance with previously reported findings [16].

Osteogenic Differentiation

Differentiation of huAFMSCs towards an osteogenic phenotype was achieved by culturing huAFMSCs in appropriate differentiation media (see Materials and Methods). Osteogenic differentiation was assessed by the increase in ALP activity, which reached statistical significance at day 7 and 14 (Fig. 2a), coupled to a remarkable increment in ALP staining at day 14 (Fig. 2b). Moreover, huAFMSCs grown in osteogenic medium for 21 days showed significant extracellular matrix mineralization, revealed by ARS staining

\section{Alkaline Phosphatase assay}
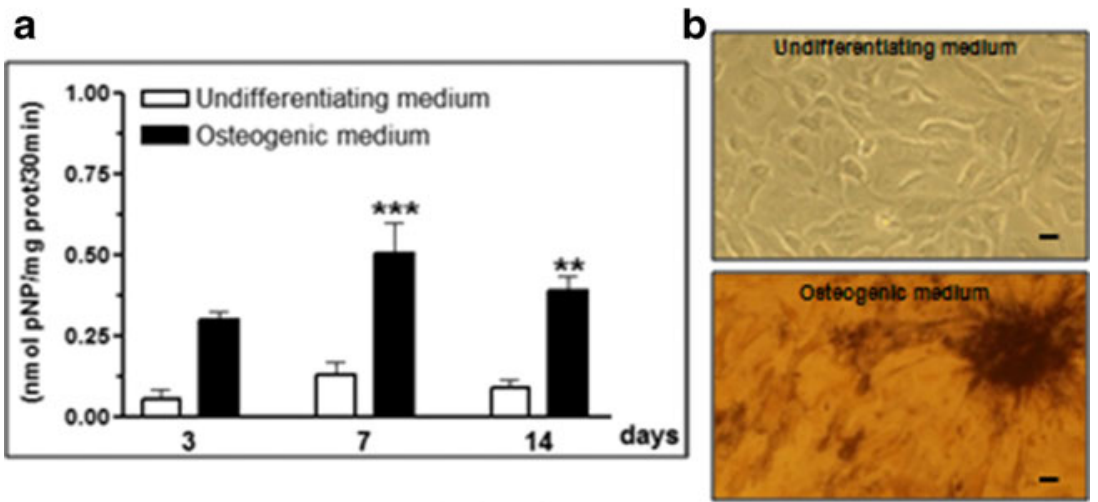

Alizarin Red S assay
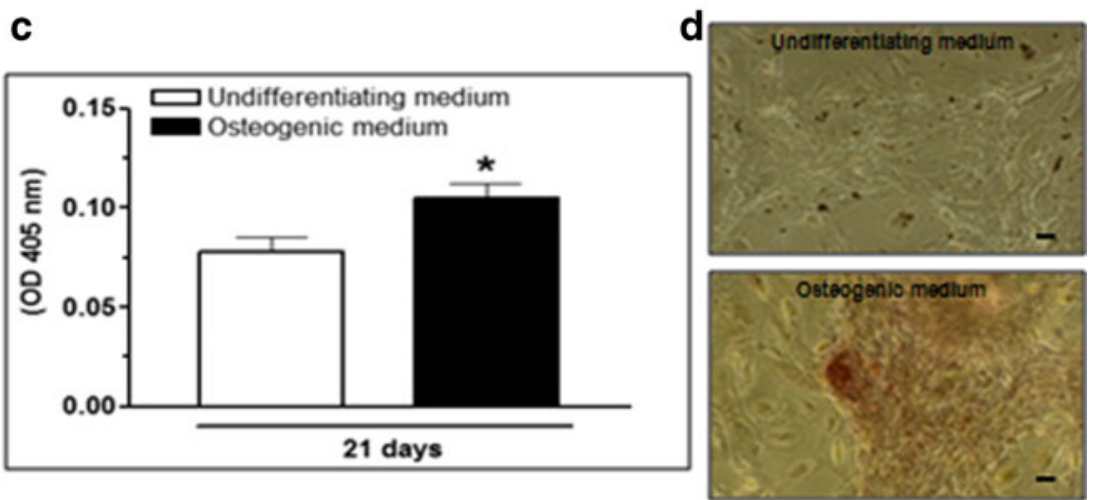

Fig. 2 Osteogenic differentiation. HuAFMSCs were exposed to differentiation medium for varying times (3-7-14 and 21 days). Osteogenesis was evaluated by monitoring ALP activity and staining (panels a-b) and extracellular matrix mineralization (panels $\mathbf{c}-\mathbf{d}$ ). $\mathbf{a}-\mathbf{b}$ ALP staining and activity were assayed as described in the Materials and Methods section. For ALP staining representative images are shown (scale bar $=80 \mu \mathrm{m}$ ), whereas the enzyme activity is expressed as nmoles of $p$-nitrophenol produced per $\mathrm{mg}$ of cell protein within $30 \mathrm{~min}(\mathrm{nmol} / \mathrm{mg}$ protein $/ 30 \mathrm{~min})$. Values are the mean $\pm \mathrm{SEM}$ of four separate experiments. c-d The mineralization of huAFMSCs, grown for 21 days in either basal or osteogenic medium, was evaluated by Alizarin Red S staining. Representative images from $n=6$ are reported (scale bar $=80 \mu \mathrm{m})(\mathbf{d})$. Quantitative analysis was carried out by spectrophotometric reading at $405 \mathrm{~nm}$ of ammonium hydroxide extracts (c). Values, expressed as units of optical density (O.D.), are the mean \pm S.E.M. of four independent experiments, with cells from 4 different donors. ${ }^{*} p<0.05,{ }^{* *} p<0.01,{ }^{* * *} p<0.001$ 
(Fig. 1d) and spectrophotometric readouts at $405 \mathrm{~nm}$ wavelength (Fig. 2c). Consistent with this, ALP and RUNX-2 mRNAs were upregulated at days 3 and 7 (Fig. $3 a$ and b)

\section{Adipogenic Differentiation}

When maintained in adipogenic medium, huAFMSCs displayed fat accumulation within the cytoplasmic vacuoles after 14 days in culture, as revealed by enhanced Oil Red Oil staining and absorbance at $500 \mathrm{~nm}$ wavelength (Fig. $4 \mathrm{~b}$ and c). They also exhibited an increase in GPDH activity, that was maximal at 10 days (Fig. 4a). Real time PCR analysis showed a significant time-dependent increase of PPAR $\gamma$ (at day 3 and 10) and FABP4 (at day 1, 3 and 10) mRNA, both considered as the main initiators of adipogenesis (Fig. 5a and b). Additionally, immunofluorescence microscopy showed the increase in PPAR $\gamma$
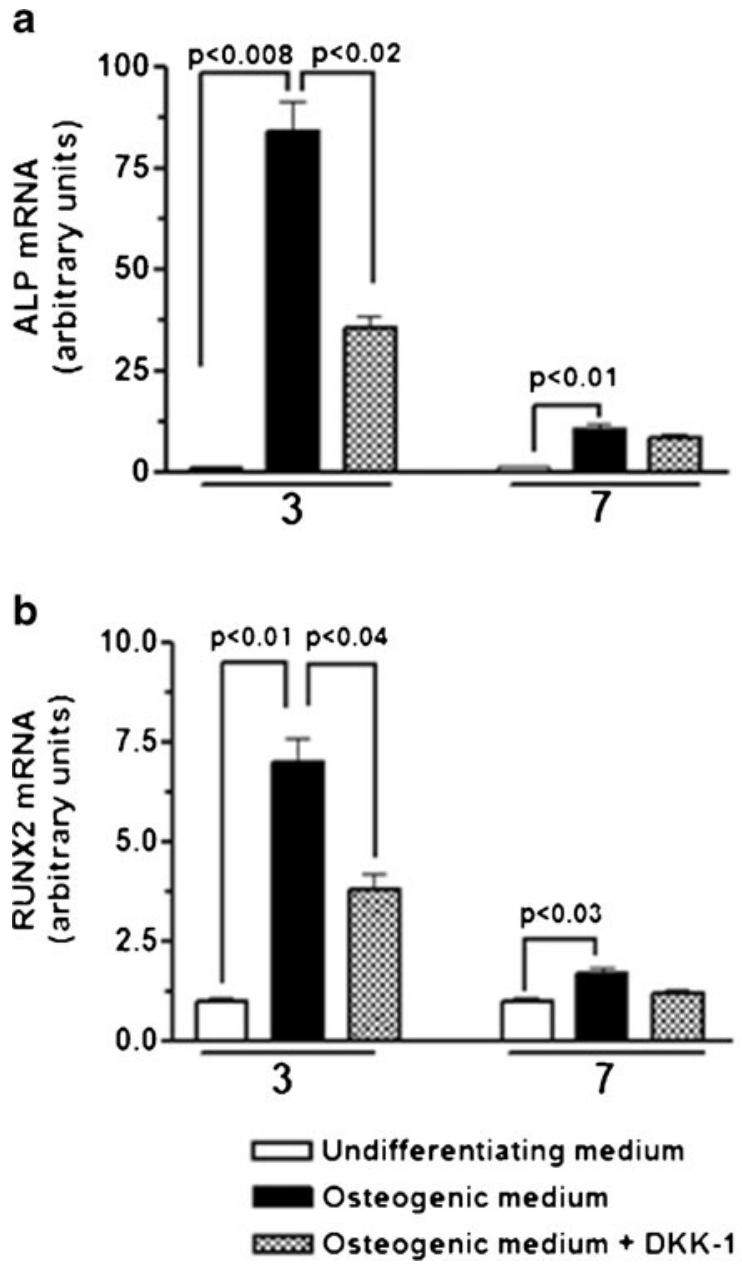

Fig. 3 Analysis of osteogenic markers. ALP and RUNX-2 expression was evaluated by real time PCR in huAFSCs cultured in undifferentiating or osteogenic for the indicated times. In some experiments, cells undergoing osteogenic differentiation, were exposed to DKK-1 (100 ng/ml), inhibitor of Wnt signal. Data are the mean \pm SEM of three separate experiments with cells from 3 different donors
Glycerol 3-Phosphate Dehydrogenase (GPDH) Assay

a

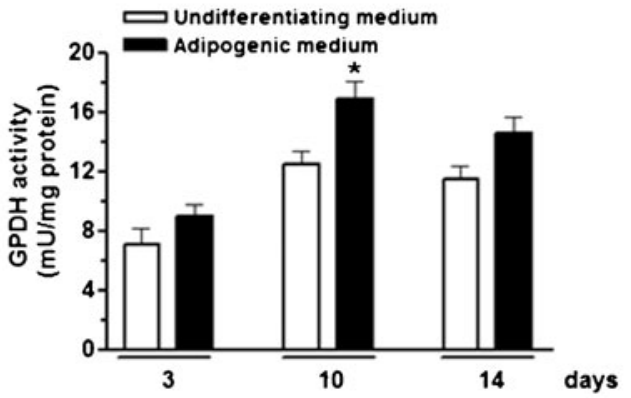

b

Oil Red Oil Assay

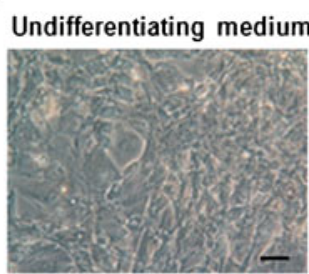

Adipogenic medium

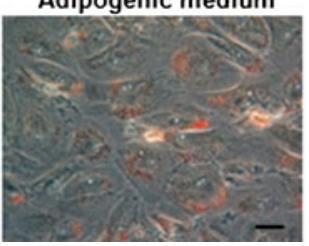

C

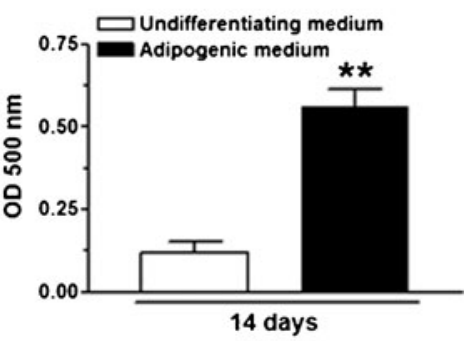

Fig. 4 Adipogenic differentiation of huAFMSCs. AFMSC differentiation upon exposure to adipogenic medium for 14 days was evaluated by GPDH activity and Oil Red Oil Staining. GPDH activity, expressed as $\mathrm{mU} / \mathrm{mg}$ protein $(1 \mathrm{mU}=1 \mathrm{n} \mu \mathrm{mol} \mathrm{NADH} / \mathrm{min})$, indicates the ability of the enzyme to consume NADH, a co-enzyme present in the reaction mixture and used by GPDH to catalyze the reaction between dihydroxyacetone phosphate and glycerol 3-phosphate (a). Oil Red Oil staining (b) and quantitation of the staining by spectrophotometer reading at $500 \mathrm{~nm}$ of the isopropanol extracts (c). Representative images are shown $($ scale bar $=80 \mu \mathrm{m})$. The bar graph shows units of optical density (O.D.). Results are the mean \pm S.E.M. of four independent experiments, with cells from 4 different donors. ${ }^{*} p<0.05$; ** $<<$ 0.01

nuclear staining in huAFMSCs maintained in adipogenic medium for 10 days as revealed by digital acquisition, processing and analysis of fluorescence (Fig. 5c).

\section{Molecular Signaling}

To dissect molecular events involved in osteogenic and adipogenic differentiantion of huAFMSCs, we examined time-dependent changes in the Wnt signaling pathway. We consistently observed a transient upregulation of Dvl-2 expression at very early stages of osteogenic induction (3 days) (Fig. 6c and d). A similar increase was observed in cultured human fibroblasts (Fig. 6a and b), routinely used as a control for osteogenesis commitment. Dvl-2 was downregulated during adipogenic differentiation (Figs. 6e 
Fig. 5 Evaluation of

adipogenic markers. PPAR $\gamma$

and FABP4 expression was

evaluated by real time PCR

assay (panels a and b). In some

experiments, cells undergoing

adipogenic differentiation, were

exposed to DKK-1 $(100 \mathrm{ng} / \mathrm{ml})$,

an inhibitor of the Wnt signal.

Data are the mean \pm SEM of

four separate experiments.

Panel c Immunofluorescence

microscopy localization of

PPAR $\gamma$ in undifferentiated

huAFMSC (lower-left),

showing exclusively the blue

fluorescence of DAPI staining, or in adipocyte-differentiated huAFMSCs (lower-right),

showing nuclear green

fluorescence from the

translocated PPAR $\gamma$. Upper

histograms represent the

analysis of fluorescence

intensity and distribution by using Meta Image Series 7.5.

Images are representative of

three separate experiments with

cells from 3 different donors,

which gave similar results a

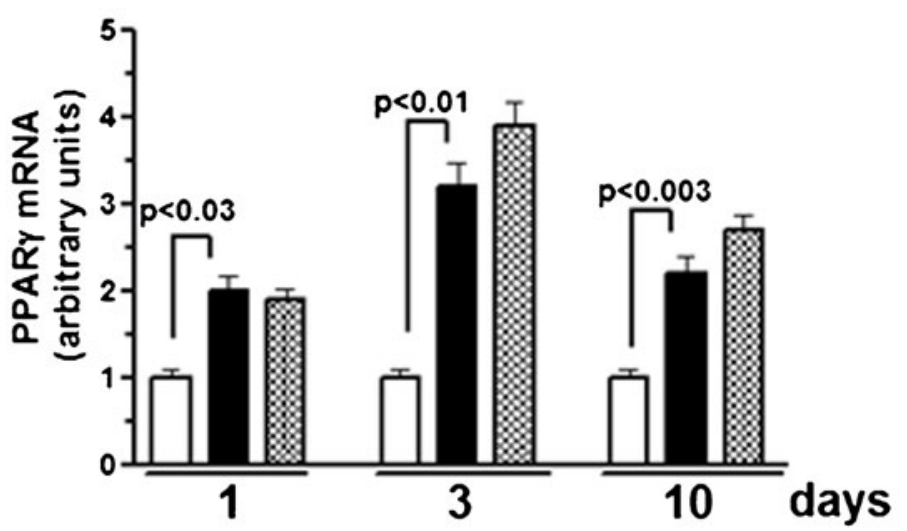

b

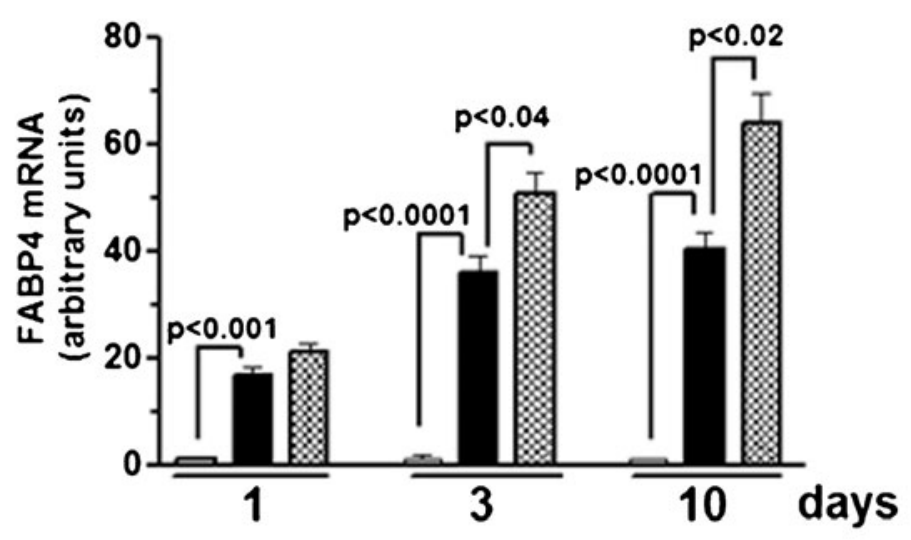

Undifferentiating medium

Adipogenic medium $m$ Adipogenic medium + DKK-1

C
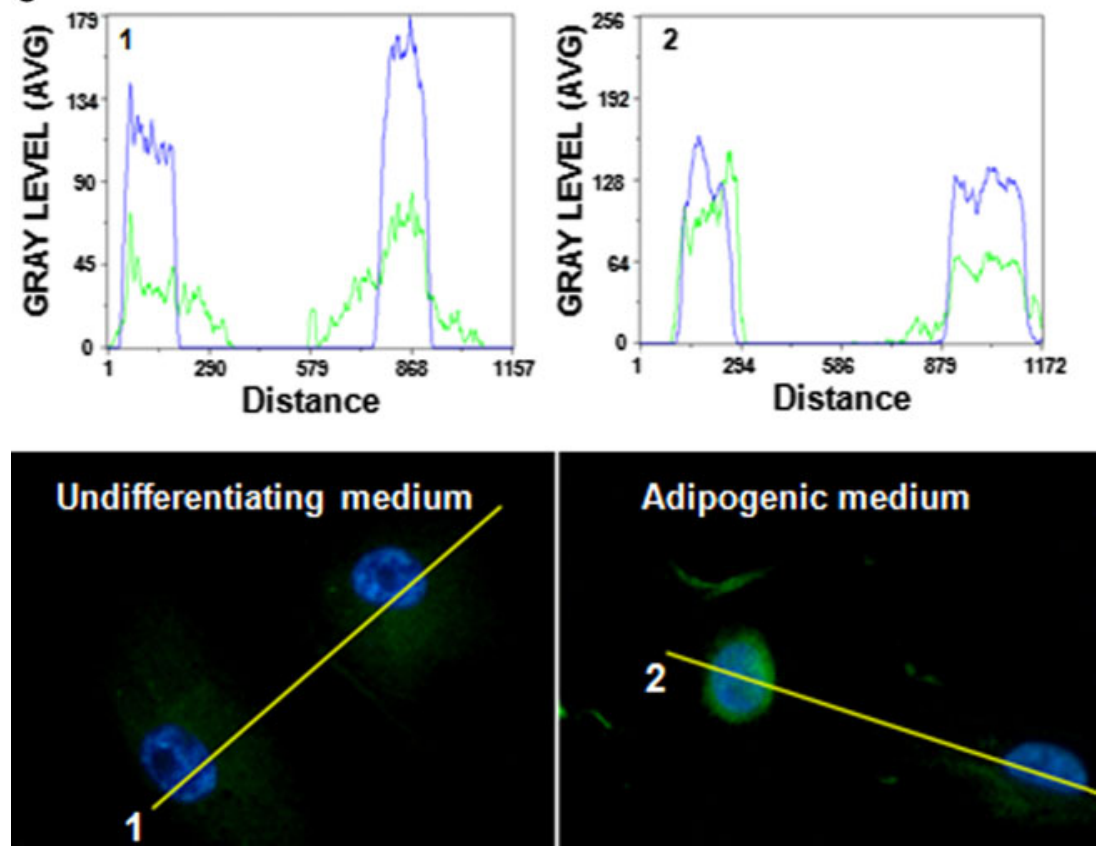


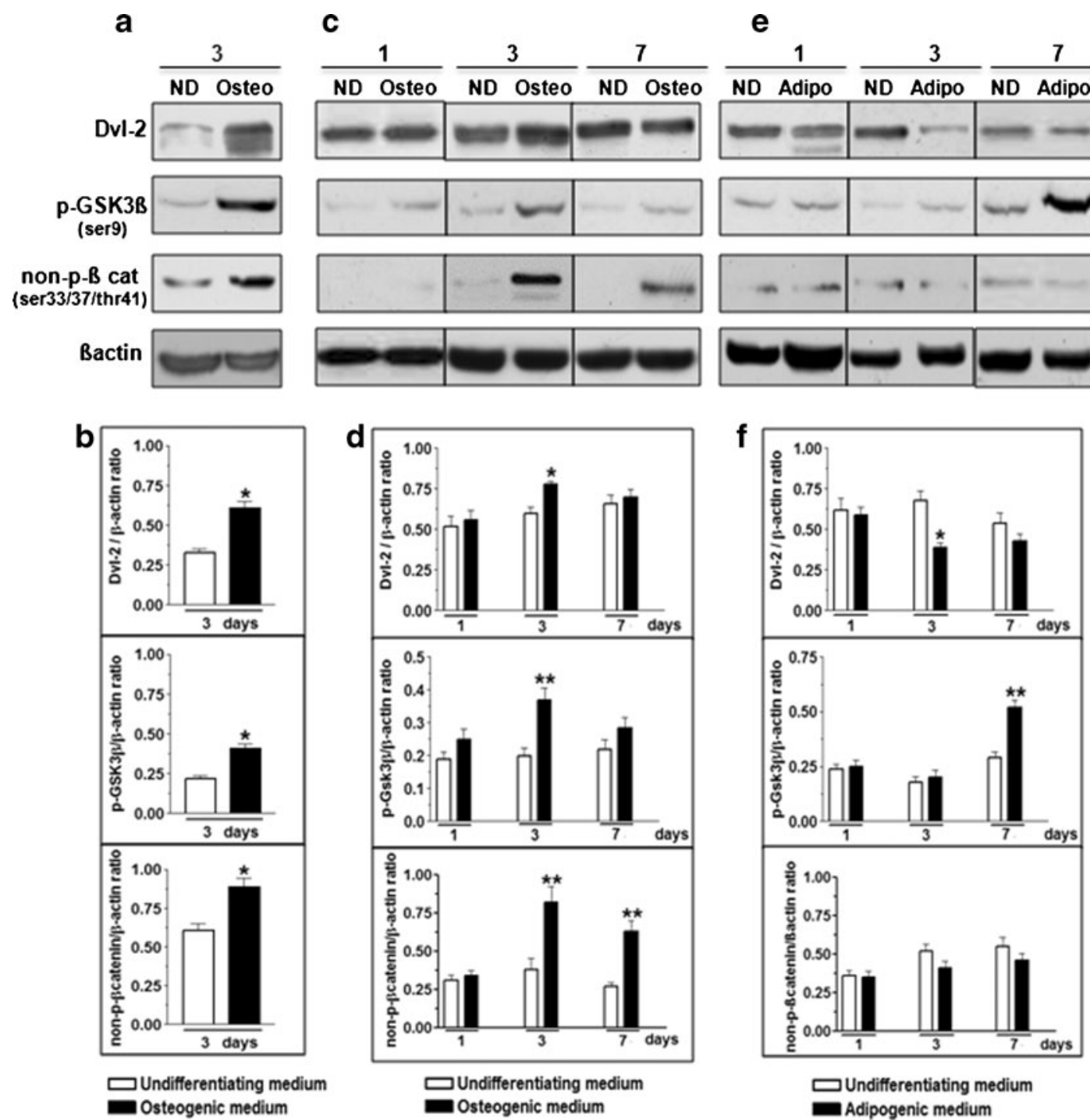

Fig. 6 Analysis of the Wnt pathway in differentiating huAFMSCs and human fibroblasts. Dvl-2, $\beta$-catenin expression and GSK $3 \beta$ phosphorylation at serine 9 were evaluated during osteogenic differentiation of fibroblasts (panel a) and huAFMSC (panel c) or adipogenic differentiation of huAFMSCs (panel e). Cells were grown in normal medium (ND) or differentiating medium for the indicated times. Dvl-2, $\beta$ catenin and phosphorylated GSK3 $\beta$ were visualized by Western blot analysis $(60 \mu \mathrm{g}$ of proteins were loaded per lane). Immunoblots, reprobed with antibodies against $\beta$ actin, to assure equal sample loading, were quantified by densitometric analysis. Values, normalized to $\beta$ actin, are reported in the histograms (panels $\mathbf{b}, \mathbf{d}$ and $\mathbf{f}$ ). Densitometric values are the mean \pm SEM of three independent experiments with cells from 3 different donors. ${ }^{*} p<0.05,{ }^{* *} p<0.01$ and f). Phosphorylation at serine 9 of GSK3ß, which inhibits the activity of this kinase, was also denoted in cells exposed to osteogenic medium for 3 days (Fig. $6 \mathrm{a}$ and c). This is consistent with the increase in the expression of $\beta$-catenin, non phosphorylated just in the sites dependent on GSK3ß activity, observed at 3 and 7 days of culture (Fig. 6a-b and c-d).

On the contrary, the induction of huAFMSCs toward the adipocyte lineage did not modify the expression of $\beta$-catenin, whereas GSK3ß phosphorylation was significantly enhanced at a later time (7 days) compared with osteogenic differentiation (Fig. 6e and f). The involvement of the Wnt signaling pathway during osteo/adipogenic differentiation of huAFMSCs was confirmed by cell exposure to Dickkopf-1 (DKK-1), a known antagonist of LRP5/6 Frizzled co-receptors [44, 45]. DKK-1 abrogated the ALP and RUNX-2 mRNA upregulation induced by osteogenic medium (Fig. 3a and b) whereas it slightly enhanced PPAR $\gamma$ expression and significantly increased FABP4 expression levels in huAFMSCs exposed to adipogenic differentiation medium (Fig. 5a and $b$ ). 


\section{Discussion}

Our study confirms that AF collected during routine amniocentesis contains multi-potential progenitor cells, which share a pattern of cell surface antigens with MSCs from other sources [13, 46], and are negative for haemotopoietic markers. This profile is typical of cultured cells, as both murine and human freshly isolated AF cells express some haemotopoietic markers [11]. Of interest, huAFMSCs express also some, but not all, human embryonic stem cell markers that likely make these cells similar but not identical to embryonic stem cells, a feature that prevents them from being tumorigenic, but endowed with a greater differentiation potential than adult stem cells [8, 47, 48]. Noteworthy, huAFMSCs stained negative (at least with the cut-off MFI ratio positivity $>2,0$ adopted for our assay) for CD117, also known as cKit. This marker is recognized as the cell surface receptor for stem cell factor and is expressed in embryonic and hematopoietic stem cells. Although cKit has also been used to select, within the heterogeneous huAFMSC population, those cells with higher differentiation potential $[14,49]$ and immunomodulatory properties [50], the expression of this protein in MSCs deriving from varying sources is at present controversial. In fact, in accordance with our findings on huAFMSCs (Fig. 1), other investigators were unable to detect CD117 expression on

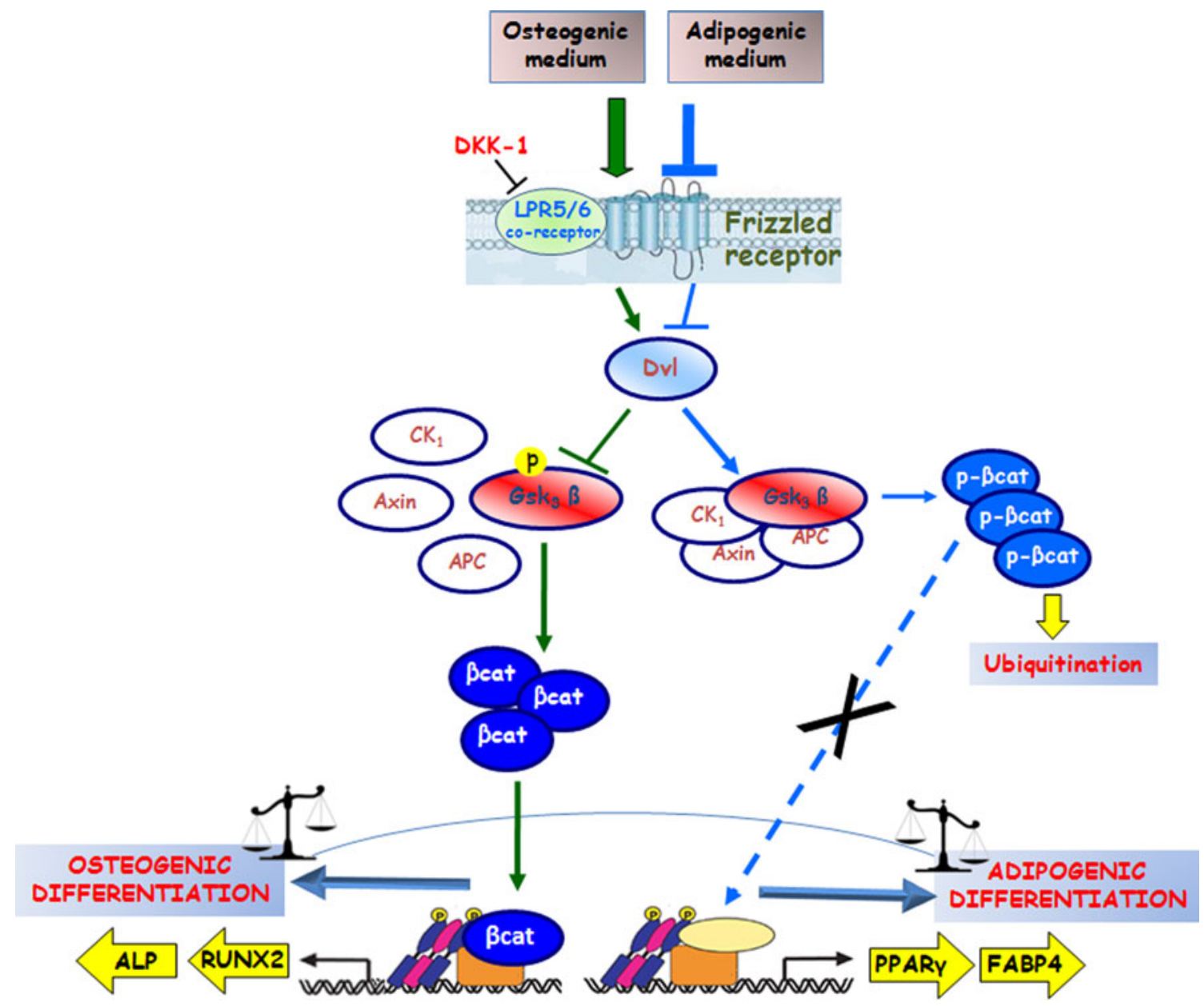

Fig. 7 Simplified network controlling the fate decisions between osteogenic and adipogenic lineages in huAFMSCs. Stem cells, in appropriate cell culture conditions, initiate osteogenic or adipogenic differentiation. Osteogenic commitment is linked to the stimulation of the canonical Wnt pathway that sequentially involves: activation of the LRP5/6 co-receptor via the frizzled receptors, signal transmission through Dishevelled ( Dvl), phosphorylation of GSK-3 $\beta$ leading to the inactivation of a cytoplasmic complex composed of CK1, Axin, APC and GSK- $3 \beta$, detachment of $\beta$-catenin phosphorylation from the complex. These events result in $\beta$-catenin stabilization and in the transcriptional activation of target genes mediated by $\beta$-catenin, i.e. the early osteogenic markers RUNX-2 and ALP. DKK1 is a secreted Wnt antagonist that may be used as a drug to inhibit Wnt signal. Adipogenic commitment involves early inhibition of Wnt signal leading to recruitment of $\beta$-catenin to the protein complex, which facilitates the GSK-3 $\beta$-dependent phosphorylation and proteosomal degradation of $\beta$-catenin. These events favors the transcription of PPAR $\gamma$ and FABP4, considered as the main initiators of adipogenesis. $A P C$, adenomatous polyposis coli; $\beta c a t, \beta$-catenin; $C K 1$, casein kinase 1; $D K K 1$, dickkopf 1; $D v l$, Dishevelled; $G S K 3 \beta$, glycogen synthase kinase $3 \beta ; L R P 5 / 6$, low density lipoprotein receptor-related protein $5 / 6$ 
MSCs [51]. A possible explanation is that $\mathrm{CD} 117^{+}$cells represent a very small percentage of the total huAFSC population and if not selected at the very early stages of cell culturing, they can be obscured to flow cytometric detection by the more abundant $\mathrm{CD} 117^{-}$cell population, which becomes more and more predominant passage after passage in culture. Noteworthy, regardless of being $\mathrm{CD} 117^{-}$, in our hands and in agreement with previous findings [52-54], huAFSC showed a good differentiation potential, even after a number of passages in culture. They were able to undergo, when grown in appropriate medium, osteogenic or adipogenic commitment, as documented by the upregulation of early molecular markers and the occurrence of phenotypic changes (Figs. 2, 3, 4 and 5). The up-regulation of RUNX-2 during the first week of the osteogenic differentiation of our cells is in agreement with the current literature. It has been, in fact, observed that RUNX-2 is key for osteoblast differentiation within the immature bone, whereas its expression has to be downregulated for cell differentiation into mature osteoblasts [55]. Likewise, ALP is considered a marker of early osteogenic differentiation [56], although the enhancement of its expression and activity during osteogenesis may occur at different times, depending on the type of MSC. Indeed, we observed early ALP expression during the osteogenic differentiation of MSC from dental tissues, whereas in other stem cells, such as those from the bone marrow, ALP expression occurs at a later time [42, 57]. Taken together, these results encourage the use of huAFMSCs in regenerative medicine [16], although extensive preclinical investigation is still needed. On the other hand, these cells may constitute a valuable model to dissect the molecular/biochemical events occurring during osteogenic/adipogenic differentiation. This may be helpful to expand our knowledge of the pathophysiology of these events as well as to engineer stem cells with more efficient and longer lasting tissue regeneration/repair activity.

With this in mind, we examined the Wnt signaling pathway in differentiating huAFMSCs. We showed that, during osteogenic commitment, Wnt pathway is activated in our cells (Fig. 6a-b), as demonstrated by the early upregulation of Dvl-2, leading to enhanced GSK3 $\beta$ phosphorylation/ inhibition, which unlocks cytosolic $\beta$-catenin expression $[25,58,59]$. Accordingly, DKK-1, an established inhibitor of the Wnt pathway, abrogated the early up-regulation of RUNX-2 and ALP, recognized as markers of cells undergoing osteogenic differentiation (Fig. 3). Taken together, these findings indicate that the Wnt signaling triggers huAFMSC commitment towards osteogenesis, as summarized in Fig. 7. They are consistent with the observation that the Wnt pathway stimulates bone formation in vitro and in vivo $[60,61]$ as well as with the finding that a decreased GSK3 $\beta$ expression/activity stimulates bone formation, via the upregulation of RUNX-2 transcription [62].
On the other hand, we found that huAFMSC commitment towards adipogenesis does not depend on Wnt signal, as demonstrated by downregulation of Dvl-2 coupled to no modification in the expression level of non phosphorylated $\beta$-catenin in the cytosol (Fig. 6c and d). Accordingly, the blockade of Wnt signaling with DKK-1 gave a significant upregulation of FABP4, a marker of adipogenic differentiation (Figs. 5 and 6). Together, these results are consistent with previous data showing that the activation of the Wnt pathway keeps pre-adipocytes in an undifferentiated state and blocks fat development in vivo $[28,63]$ and that the inhibition of the $\mathrm{Wnt} / \beta$-catenin signaling promotes adipogenesis [64]. Along these lines, the observation of a delayed GSK3 $\beta$ phosphorylation occurs during adipogenic commitment (Fig. 6c) suggests that the activity of this enzyme is needed in the initial phase of huAFSC differentiation into adipocytes. This is consistent with previous reports showing that: i) GSK3 $\beta$ activity is required to enable PPAR $\gamma$-dependent $\beta$-catenin degradation during pre-adipocyte differentiation [65]; ii) inhibition of GSK $3 \beta$ activity, restricted to the early step of differentiation, is sufficient to impair adipogenic differentiation of human adipose-derived stem cells [66]. Moreover, since the canonical Wnt signal does not appear to be activated during adipogenic differentiation of huAFMSCs, the delayed GSK3 $\beta$ inactivation (Fig. 6c) might be attributed to insulin, which is present in the adipogenic culture medium and is essential for adipogenic differentiation. Insulin can, in fact, induce GSK3 $\beta$ (ser9) phosphorylation/inhibition via the activation of the phosphoinositide 3 kinase/protein kinase B pathway (reviewed in [67]).

In conclusion, our study provides an accurate phenotypic characterization of huAFMSCs and establishes that the canonical Wnt/ßcatenin signaling pathway triggers the osteogenic commitment of these cells. On the contrary, the early inactivation of this pathway promotes adipogenic differentiation. Thus, modulating the Wnt signaling may represent a novel approach to direct cells towards a more definite differentiation that may result useful in the clinical use of huAFMSCs in regenerative medicine. Future studies are however awaited to assess the validity of this strategy.

Acknowledgments This study was partially supported by a grant to StemTeCh Group from CARICHIETI Foundation and also by funds to R.C. and F.C. from the Italian Ministry of Education, University and Research (MIUR).

Conflict of Interest The authors have no conflict of interest to disclose.

Open Access This article is distributed under the terms of the Creative Commons Attribution License which permits any use, distribution, and reproduction in any medium, provided the original author(s) and the source are credited. 


\section{References}

1. Jiang, Y., Jahagirdar, B. N., Reinhardt, R. L., Schwartz, R. E., Keene, C. D., Ortiz-Gonzalez, X. R., et al. (2002). Pluripotency of mesenchymal stem cells derived from adult marrow. Nature, 418(6893), 41-49.

2. Baksh, D., Song, L., \& Tuan, R. S. (2004). Adult mesenchymal stem cells: characterization, differentiation and application in cell therapy. Molecular Medicine, 8, 301-316.

3. Shekkeris, A. S., Jaiswal, P. K., \& Khan, W. S. (2012). Clinical applications of mesenchymal stem cells in the treatment of fracture non-union and bone defects. Current Stem Cell Research \& Therapy, 7(2), 127-133.

4. Khojasteh, A., Behnia, H., Dashti, S. G., \& Stevens, M. (2012). Current trends in mesenchymal stem cell application in bone augmentation: a review of the literature. Journal of Oral and Maxillofacial Surgery, 70(4), 972-982.

5. Jones, E., \& Yang, X. (2011). Mesenchymal stem cells and bone regeneration: current status. Injury, 42(6), 562-568.

6. Wang, S., Qu, X., \& Zhao, R. C. (2012). Clinical applications of mesenchymal stem cells. Journal of Hematology \& Oncology, 5, 19.

7. Tokalov, S. V., Grüner, S., Schindler, S., Wolf, G., Baumann, M., $\&$ Abolmaali, N. (2007). Age-related changes in the frequency of mesenchymal stem cells in the bone marrow of rats. Stem Cells and Development, 16(3), 439-446.

8. Sessarego, N., Parodi, A., Podestà, M., Benvenuto, F., Mogni, M., Raviolo, V., et al. (2008). Multipotent mesenchymal stromal cells from amniotic fluid: solid perspectives for clinical application. Haematologica, 93(3), 339-346.

9. You, Q., Tong, X., Guan, Y., Zhang, D., Huang, M., Zhang, Y., et al. (2009). The biological characteristics of human third trimester amniotic fluid stem cells. Journal of International Medicine Research, 37(1), 105-112.

10. Miranda-Sayago, J. M., Fernandez-Arcas, N., Benito, C., ReyesEngel, A., Carrera, J., \& Alonso, A. (2011). Lifespan of human amniotic fluid-derived multipotent mesenchymal stromal cells. Cytotherapy, 13, 572-581.

11. Ditadi, A., de Coppi, P., Picone, O., Gautreau, L., Smati, R., Six, E., et al. (2009). Human and murine amniotic fluid c-Kit+Lin- cells display hematopoietic activity. Blood, 113(17), 3953-3960.

12. Moschidou, D., Mukherjee, S., Blundell, M. P., Drews, K., Jones, G. N., Abdulrazzak, H., et al. (2012). Valproic acid confers functional pluripotency to human amniotic fluid stem cells in a transgene-free approach. Molecular Therapy, 20(10), 1953-1967.

13. Roubelakis, M. G., Trohatou, O., \& Anagnou, N. P. (2012). Amniotic fluid and amniotic membrane stem cells: marker discovery. Stem Cells International, 2012, 107836.

14. Zheng, Y. B., Gao, Z. L., Xie, C., Zhu, H. P., Peng, L., Chen, J. H., et al. (2008). Characterization and hepatogenic differentiation of mesenchymal stem cells from human amniotic fluid and human bone marrow: a comparative study. Cell Biology International, 32(11), 1439-1448.

15. Kang, N. H., Hwang, K. A., Kim, S. U., Kim, Y. B., Hyun, S. H., Jeung, E. B., et al. (2012). Potential antitumor therapeutic strategies of human amniotic membrane and amniotic fluid-derived stem cells. Cancer Gene Therapy, 19(8), 517-522.

16. Joo, S., Ko, I. K., Atala, A., Yoo, J. J., \& Lee, S. J. (2012). Amniotic fluid-derived stem cells in regenerative medicine research. Archives of Pharmacological Research, 35(2), 271-280.

17. De Coppi, P., Bartsch, G., Jr., Siddiqui, M. M., Xu, T., Santos, C. C., Perin, L., et al. (2007). Isolation of amniotic stem cell lines with potential for therapy. Nature Biotechnology, 25, 100-106.

18. Phermthai, T., Suksompong, S., Tirawanchai, N., Issaragrisil, S., Julavijitphong, S., Wichitwiengrat, S., et al. (2012) Epigenetic analysis and suitability of amniotic fluid stem cells for research and therapeutic purposes. Stem Cells Development Dec 18 [Epub ahead of print].

19. Moschidou, D., Mukherjee, S., Blundell, M. P., Jones, G. N., Atala, A. J., Thrasher, A. J., et al. (2013). Human mid-trimester amniotic fluid stem cells cultured under embryonic stem cell conditions with valproic acid acquire pluripotent characteristics. Stem Cells and Development, 22(3), 444-458.

20. Abdulrazzak, H., De Coppi, P., \& Guillot, P. V. (2012) Therapeutic potential of amniotic fluid stem cells. Current Stem Cell Research \& Therapy Nov. 2012 [Epub ahead of print].

21. Pittenger, M. F., Mackay, A. M., Beck, S. C., Jaiswal, R. K., Douglas, R., Mosca, J. D., et al. (1999). Multilineage potential of adult human mesenchymal stem cells. Science, 284, 143-147.

22. Caplan, A. I., \& Bruder, S. P. (2001). Mesenchymal stem cells: building blocks for molecular medicine in the 21 st century. Trends in Molecular Medicine, 7(6), 259-264.

23. Bhattacharyya, S., Kumar, A., \& Lal Khanduja, K. (2012). The voyage of stem cell toward terminal differentiation: a brief overview. Acta Biochimica et Biophysica Sinica (Shanghai), 4(6), 463475.

24. Rao, T. P., \& Kühl, M. (2010). An updated overview on Wnt signaling pathways: a prelude for more. Circulation Research, 106(12), 1798-1806.

25. Yavropoulou, M. P., \& Yovos, J. G. (2007). The role of the Wnt signaling pathway in osteoblast commitment and differentiation. Hormones, 6(4), 279-294.

26. Goldring, S. R., \& Goldring, M. B. (2007). Eating bone or adding it: the Wnt pathway decides. Nature Medicine, 13(2), 133-134.

27. Macsai, C. E., Foster, B. K., \& Xian, C. J. (2008). Role of Wnt signaling in bone growth, remodeling skeletal disorders and fracture repair. Journal of Cellular Physiology, 215, 578-587.

28. Christodoulides, C., Lagathu, C., Sethi, J. K., \& Vidal-Plug, A. (2009). Adipogenesis and Wnt signaling. Trends in Endocrinology and Metabolism, 220(1), 16-24.

29. de Boer, J., Siddappa, R., Gaspar, C., van Apeldoorn, A., Fodde, R., \& van Blitterswijk, C. (2004). Wnt signaling inhibits osteogenic differentiation of human mesenchymal stem cells. Bone, 34(5), 818-826.

30. Cho, H. H., Kim, Y. J., Kim, S. J., Kim, J. H., Bae, Y. C., Ba, B., et al. (2006). Endogenous Wnt signaling promotes proliferation and suppresses osteogenic differentiation in human adipose derived stromal cells. Tissue Engineering, 12(1), 111-121.

31. Scheller, E. L., Chang, J., \& Wang, C. Y. (2008). Wnt/ $\beta$-catenin inhibits dental pulp stem cell differentiation. Journal of Dental Research, 87(2), 126-130.

32. Liu, G., Vijayakumar, S., Grumolato, L., Arroyave, R., Qiao, H., Akiri, G., et al. (2009). Canonical Wnts function as potent regulators of osteogenesis by human mesenchymal stem cells. The Journal of Cell Biology, 185(1), 67-75.

33. Tang, N., Song, W. X., Luo, J., Luo, X., Chen, J., Sharff, K. A., et al. (2009). BMP-9-induced osteogenic differentiation of mesenchymal progenitors requires functional canonical Wnt/beta-catenin signalling. Journal of Cellular and Molecular Medicine, 13(8B), 2448-2464.

34. Lanuti, P., Fuhrmann, S., Lachmann, R., Marchisio, M., Miscia, S., \& Kern, F. (2009). Simultaneous characterization of phosphoproteins and cell cycle in activated $\mathrm{T}$ cell subsets. International Journal of Immunopathology and Pharmacology, 22, 689-698.

35. Lanuti, P., Santilli, F., Marchisio, M., Pierdomenico, L., Vitacolonna, E., Santavenere, E., et al. (2012). A novel flow cytometric approach to distinguish circulating endothelial cells from endothelial microparticles: relevance for the evaluation of endothelial dysfunction. Journal of Immunological Methods, 380(1-2), 16-22.

36. Lanuti, P., Ciccocioppo, F., Bonanni, L., Marchisio, M., Lachmann, R., Tabet, N., et al. (2012). Amyloid-specific T-cells differentiate Alzheimer's disease from Lewy body dementia. Neurobiology of Aging, 33(11), 2599-2611. 
37. D’Alimonte, I., Nargi, E., Mastrangelo, F., Falco, G., Lanuti, P., Marchisio, M., et al. (2011). Vascular endothelial growth factor enhances in vitro proliferation and osteogenic differentiation of human dental pulp stem cells. Journal of Biological Regulators and Homeostatic Agents, 25(1), 57-69.

38. Gregory, C. A., Gunn, W. G., Peister, A., \& Prockop, D. J. (2004). An Alizarin red-based assay of mineralization by adherent cells in culture: comparison with cetylpyridinium chloride extraction. Analytical Biochemistry, 329, 77-84.

39. Laflamme, C., Curt, S., \& Rouabhia, M. (2010). Epidermal growth factor and bone morphogenetic proteins upregulate osteoblast proliferation and osteoblastic markers and inhibit bone nodule formation. Archives of Oral Biology, 55, 689-701.

40. Hajra, A. K., Larkins, L. K., Das, A. K., Hemati, N., Erickson, R. L., \& MacDougald, O. A. (2000). Induction of the peroxisomal glycerolipid-synthesizing enzymes during differentiation of 3T3L1 adipocytes. Role in triacylglycerol synthesis. Journal of Biological Chemistry, 275(13), 9441-9446.

41. D'Alimonte, I., Ballerini, P., Nargi, E., Buccella, S., Giuliani, P., Di Iorio, P., et al. (2007). Staurosporine-induced apoptosis in astrocytes is prevented by $\mathrm{A}_{1}$ adenosine receptor activation. Neuroscience Letters, 418(1), 66-71.

42. Tetè, S., Nargi, E., Mastrangelo, F., Zizzari, V., D’Apolito, G., Traini, T., et al. (2008). Changes in matrix extracellular phosphoglycoprotein expression before and during in vitro osteogenic differentiation of human dental papilla mesenchymal cells. International Journal of Immunopathology and Pharmacology, 21(2), 309-318.

43. Sulpizio, M., Falone, S., Amicarelli, F., Marchisio, M., Di Giuseppe, F., Eleuterio, E., et al. (2011). Molecular basis underlying the biological effects elicited by extremely low-frequency magnetic field (ELF-MF) on neuroblastoma cells. Journal of Cell Biochemistry, 112(12), 3797-3806.

44. Glinka, A., Wu, W., Delius, H., Monaghan, A. P., Blumenstock, C., \& Niehrs, C. (1998). Dickkopf-1 is a member of a new family of secreted proteins and functions in head induction. Nature, 391(6665), 357-362.

45. Fedi, P., Bafico, A., Nieto Soria, A., Burgess, W. H., Miki, T., Bottaro, D. P., et al. (1999). Isolation and biochemical characterization of the human Dkk-1 homologue, a novel inhibitor of mammalian Wnt signaling. Journal of Biological Chemistry, 274(27), 19465-19472.

46. Dominici, M., Le Blanc, K., Mueller, I., Slaper-Cortenbach, I., Marini, F., Krause, D., et al. (2006). Minimal criteria for defining multipotent mesenchymal stromal cells. The International Society for Cellular Therapy position statement. Cytotherapy, 8(4), 315-317.

47. Rosner, M., Dolznig, H., Schipany, K., Mikula, M., Brandau, O., \& Hengstschläger, M. (2011). Human amniotic fluid stem cells as a model for functional studies of genes involved in human genetic diseases or oncogenesis. Oncotarget, 2(9), 705-712.

48. Antonucci, I., Stuppia, L., Kaneko, Y., Yu, S., Tajiri, N., Bae, E. C., et al. (2011). Amniotic fluid as a rich source of mesenchymal stromal cells for transplantation therapy. Cell Transplantation, 20(6), 789-795

49. Arnhold, S., Glüer, S., Hartmann, K., Raabe, O., Addicks, K., Wenisch, S., et al. (2011). Amniotic-fluid stem cells: growth dynamics and differentiation potential after a CD117-based selection procedure. Stem Cells International, 2011, 715341.

50. Moorefiled, E. C., McKee, E. E., Solchaga, L., Orlando, G., Yoo, J. J., Walker, S., et al. (2011). Cloned, CD117 selected human amniotic fluid stem cells are capable of modulating the immune response. Plos One, 6(10), e26535.
51. Wagner, W., Wein, F., Seckinger, A., Frankhauser, M., Wirkner, U., Krause, U., et al. (2005). Comparative characteristics of mesenchymal stem cells from human bone marrow, adipose tissue, and umbilical cord blood. Experimental Hematology, 33, 1402-1416.

52. Poloni, A., Maurizi, G., Babini, L., Serrani, F., Berardinelli, E., Mancini, S., et al. (2011). Human mesenchymal stem cells from chorionic villi and amniotic fluid are not susceptible to transformation after extensive in vitro expansion. Cell Transplantation, 20(5), 643-654.

53. Chen, Q., Xiao, P., Chen, J. N., Cai, J. Y., Cai, X. F., Ding, H., et al. (2010). AFM studies of cellular mechanics during osteogenic differentiation of human amniotic fluid-derived stem cells. Analytical Sciences, 26(10), 1033-1037.

54. Bai, J., Wang, Y., Liu, L., Chen, J., Yang, W., Gao, L., et al. (2012). Human amniotic fluid-derived c-kit( + ) and c-kit(-) stem cells: growth characteristics and some differentiation potential capacities comparison. Cytotechnology, 64(5), 577-589.

55. Komori, T. (2010). Regulation of bone development and extracellular matrix protein genes by RUNX2. Cellular Tissue Research, 339, 189-195.

56. Koch, H., Jadlowiec, J. A., \& Campbell, P. G. (2005). Insulin-like growth factor-I induces early osteoblast bene expression in human mesenchymal stem cells. Stem Cells and Development, 14(6), 621631.

57. Costa, M. A., Barbosa, A., Neto, E., Sá-e-Sousa, A., Freitas, R., Neves, J. M., et al. (2011). On the role of subtype selective adenosine receptor agonists during proliferation and osteogenic differentiation of human primary bone marrow stromal cells. Journal of Cellular Physiology, 226, 1353-1366.

58. Yang-Snyder, J., Miller, J. R., Brown, J. D., Lai, C. J., \& Moon, R. T. (1996). A frizzled homolog functions in a vertebrate Wnt signaling pathway. Current Biology, 6(10), 1302-1306.

59. Gumbiner, B. M. (1995). Signal transduction of beta-catenin. Current Opinion in Cell Biology, 7(5), 634-640.

60. Day, T. F., Guo, X., Garrett-Beal, L., \& Yang, Y. (2005). Wnt/ $\beta$ catenin signaling in mesenchymal progenitors controls osteoblast and chondrocyte differentiation during vertebrate skeletogenesis. Developmental Cell, 8, 739-750.

61. Glass, D. A., 2nd, Bialek, P., Ahn, J. D., Starbuck, M., Patel, M. S., Clevers, H., et al. (2005). Canonical Wnt signaling in differentiated osteoblasts controls osteoclast differentiation. Developmental Cell, $8,751-764$

62. Kugimiya, F., Kawaguchi, H., Ohba, S., Kawamura, N., Hirata, M., Chikuda, H., et al. (2007). GSK-3beta controls osteogenesis through regulating Runx2 activity. PLoS One, 2(9), e837.

63. Ross, S. E., Hemati, N., Longo, K. A., Bennett, C. N., Lucas, P. C., Erickson, R. L., et al. (2000). Inhibition of adipogenesis by Wnt signaling. Science, 289, 950-953.

64. Takada, I., Kouzmenko, A. P., \& Kato, S. (2009). Wnt and PPARgamma signaling in osteoblastogenesis and adipogenesis. Nature Reviews. Rheumatology, 55(8), 442-447.

65. Farmer, S. R. (2005). Regulation of PPARgamma activity during adipogenesis. International Journal of Obesity (London), 29 (Suppl 1), S13-S16.

66. Zaragosi, L. E., Wdziekonski, B., Fontaine, C., Villageois, P., Peraldi, P., \& Dani, C. (2008). Effects of GSK3 inhibitors on in vitro expansion and differentiation of human adipose-derived stem cells into adipocytes. BMC Cell Biology, 9.

67. Forde, J. E., \& Dale, T. C. (2007). Glycogen synthase kinase 3: a key regulator of cellular fate. Cellular and Molecular Life Sciences, 64(15), 1930-1944. 